\author{
EISSN:2706-7920 ISSN: 2077-4435 \\ DOI: $10.36632 / \mathrm{csi} / 2021.10 .3 .40$ \\ Journal homepage: www.curresweb.com \\ Pages: 454-465
}

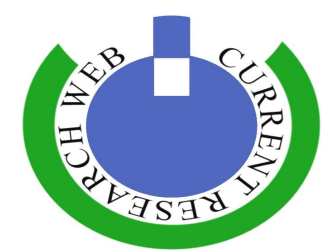

\title{
Long Term Soft Denture Liners; Current Status, Clinical Performance and Limitations
}

\section{Mohamed H. Abdelnabi ${ }^{1}$ and Amal A. Swelem ${ }^{2}$}

\author{
${ }^{1}$ Professor, Oral and Maxillofacial Prosthodontic Department, Faculty of Dentistry, King Abdulaziz \\ University, Jeddah, Saudi Arabia; and Removable Prosthodontic Department, Faculty of Dentistry, \\ Minia University, Egypt. \\ ${ }^{2}$ Professor, Oral and Maxillofacial Prosthodontic Department, Faculty of Dentistry, King Abdulaziz \\ University, Jeddah, Saudi Arabia; and Removable Prosthodontic Department, Faculty of Oral and \\ Dental Medicine, Cairo University, Egypt.
}

Received: 25 August $2021 \quad$ Accepted: 20 Sept. $2021 \quad$ Published: 30 Sept. 2021

\begin{abstract}
Long term soft liners are used to alleviate discomfort and tissue damage associated with complete denture intolerance due to functional factors. This article reviews long term soft liners as regards the basic classification and both clinical and patient centered treatment outcomes. Each of the authors independently conducted a manual and electronic search of the English literature up till December 2020. Initially the titles were extracted based on predetermined inclusion and exclusion criteria. Abstracts of the selected titles that both authors agreed upon were then screened. The last stage was the extraction of relevant data and including it under headings in a narrative review of literature format. It was concluded that, in properly selected cases, long term soft liners could be considered an affordable solution that significantly improve clinical and patient centered treatment outcomes. Clinical outcomes included maximum occlusal forces, effect on mandibular movements during the chewing cycle, masticatory performance, effect on electromyographic recordings, in addition to fungal overgrowth and its consequences on denture hygiene and related mucosal inflammation. Patient centered parameters included patient self-assessment, satisfaction, preference and impact on Oral Health Related Quality of Life. Proper selection of the type of soft liner plays a crucial role in reaching a successful outcome. Major concerns with long term soft liners include loss of resiliency, fungal overgrowth, debonding and hygiene maintenance. This review also discussed the limitations of the available studies. Clinical studies recruited only complete denture patients with good prognosis and not the compromised cases that actually need management with soft liners the most. It was thus suggested that the functionality of this category of complete denture wearers could be an area of focus for upcoming randomized controlled clinical studies.
\end{abstract}

Keywords: Long term soft liners, oral health related quality of life, patient satisfaction, mandibular movements, electromygraphy, masticatory performance

\section{Introduction}

Conventional complete dentures still remain the most important treatment modality for completely edentulous patients (Palla et al., 2015). Implants have greatly improved the management of complete edentulism (Feine et al., 2002). Nevertheless, in many places in the world, implants are still not practical for financial, medical and psychological reasons (Kimoto et al., 2006). The need for complete dentures still exists especially when taking into consideration the increase in the elderly population (Douglass et al., 2002; Peterson et al., 2005; Felton et al., 2011). This demand for conventional complete dentures imposes challenges when managing cases with compromised denture foundation. Soft liners have been used to manage such cases. This category of polymeric materials act as a cushion that helps absorb some of the masticatory forces. This feature results in a more even pattern of load distribution. Mechanical irritation to the underlying mucosa is thus reduced and 
consequently improves overall patient satisfaction (Wright, 1994; Kawano et al., 1993; Shim et al., 2000; Taguchi et al., 2001; Kimoto et al., 2008).

The objective of this study was to review the available literature reporting on the clinical performance and limitations of the currently available long term soft liners. Each of the authors conducted independently manual followed by electronic search in the dental literature available in English. Electronic databases were MEDLINE, Embase, Cochraine library and Google up till December 2020. Search terms included: long term soft liners; resilient liners; clinical performance, maximum occlusal forces; chewing cycle; masticatory performance; electromyography; hygiene; patient satisfaction; patient preference; Oral Health Related Quality of Life. The inclusion criteria were: 1. Peer reviewed scientific journals; 2. English language articles. The exclusion criterion was articles investigating only short term tissue conditioners. A systematic approach was implemented to conduct the electronic search. Article titles were acquired in the first stage and analyzed for suitability. In the second stage abstracts were screened. In the third stage full text articles were studied to extract the relevant data. Collected data were then categorized under headings in a narrative review of literature format.

\section{Basic definition and classification of soft liners}

Resilient denture liners are defined in "The Glossary of Prosthodontic Terms" (2017) to be a group of materials that are applied as liners to the intaglio surface of removable prostheses including complete dentures, partial dentures and extra oral maxillofacial prostheses. This category of materials was further classified into interim and definitive. The former group uses as an example ethyl methacrylate and phthalate plasticizers while the latter definitive group includes processed silicone.

A closely related group of materials namely tissue conditioners were defined as resilient liner resins placed in removable prostheses for a short duration to give a chance for tissue healing. In addition, this category of materials could be used for functional relining with the aim of evaluating denture function and patient acceptance before proceeding with the laboratory processing of denture relines (The Glossary of Prosthodontic Terms, 2017).

Braden et al., (1995) classified soft liners based on duration of use into short and long term varieties. They specified that the long term type could maintain its properties for at least 4 weeks. The serviceability of this variety may extend to a period of months or years.

Long term soft liners in common use generally fall into one of two groups, acrylic and silicone based. The acrylic based category is usually presented as a powder-liquid system. Phoenix (2003) and Rodrigues et al., (2013) explained the role of the plasticizer molecules in the formulation of this type of liners, which is namely to decrease the glass transition temperature which in turn makes the material softer. A major drawback of plasticizer incorporation is it leaches out because it is not bound to the soft liner resin. This phenomenon results in deterioration of the mechanical properties of the soft liner with time.

The silicone based group of soft liners is available in two basic varieties. The first is a one component heat cured material also known as High Temperature Vulcanized silicones (HTV). The second variety is a two paste system cross linked at room temperature thus known as Room Temperature Vulcanized silicones (RTV). The RTV variety is also known as chair side silicone resilient liners as curing and cross linking can take place in relatively low temperature of the oral cavity (Chladek et al., 2014). Kiat-Amnuay et al., (2005) reported that RTV silicones have final hardness values that are generally lower than HTV silicones.

\section{Methodologies implemented to assess clinical and patient centered outcomes with long term soft liners}

Studies that assessed the clinical performance of long term soft liners evaluated objective and/or subjective parameters. Clinical studies, on the one hand, assess a number of objective parameters as maximum occlusal forces, effect on mandibular movements during the chewing cycle, masticatory performance, effect on electromyographic recordings in addition to fungal overgrowth and its consequences on denture hygiene and related mucosal inflammation (Chladek et al., 2014; Palla et al., 2015). Subjective patient centered evaluation, on the other hand, resorted to validated questionnaires that give information about patient perceptions, self-assessment, satisfaction, preference, in addition to impact on Oral Health Related Quality of Life (Pisani et al., 2012; Kimoto et al., 2014). 


\section{Effect on maximum occlusal forces}

Studies used different methodologies to assess maximum occlusal forces with soft liners. Murata et al., (2002) and Kimoto et al., (2006) resorted to Dental Prescale System for that purpose. Patients were asked to occlude in the intercuspal position applying maximum occlusal forces on a pressure sensitive sheet that was then scanned and analyzed by a computer. Color changes of the pressure detecting sheet in addition to the area to which force was applied were monitored. Murata et al., (2002) compared a number of short and long term soft liners for a short evaluation period of 1 week. Long term acrylic based soft liners were superior followed by long term silicone liners then temporary acrylic based soft liners. Conventional heat cured acrylic resin showed the lowest values. The authors explained their findings by the short term superior rheological properties of cross linked acrylic resin based liners. This group showed favorable viscoelastic behavior which resulted in a cushioning effect that is comparable to the oral mucosa. It was however pointed out that on the long term, silicone liners are known to be more durable. Kalachandra et al., (1995) emphasized that an additional advantage of silicone soft liners are the lower water absorption and lower component solubility. Murata et al., (2002) thus suggested that the ideal soft liners should combine the advantageous viscoelastic properties of acrylic resin based soft liners and the durability of the silicone based soft liners.

Kimoto et al., (2006), on the other hand, using the same methodology of Dental Prescale System reported different results. They compared silicone based liners to conventional heat cured acrylic resin complete dentures in a randomized controlled cross over study. The duration of use of each denture base material was 3 months. No statistically significant differences between the groups in maximum bite force were reported. It is worth mentioning that the authors reported superior masticatory performance with the silicone liners. They interpreted their results based on the assumption that maximum bite force is related to static compression of the mucoperiosteum. Nevertheless, masticatory performance is dependent not only on static but also dynamic compression that takes place during the masticatory cycle. Based on their findings, silicone based soft liners is more efficient in distributing stresses under dynamic compression conditions.

Hayakawa et al., (2000) and Abdelnabi and Swelem (2020) used force transducers to measure maximum bite force. Hayakawa et al., (2000) used a hand held force meter to compare long term fluoropolymer soft liners to conventional heat cured acrylic resin dentures. Their study was short termed for 1 week duration. Patients with soft liners showed a significant increase in maximum bite force by one third. The interpretation of their results was in accordance with that of Emura et al., (1992), who reported similar results. They attributed the increase in maximum biting force to the improvement in the capacity of the residual ridges to bear stresses because of the more even distribution of applied occlusal forces over a large area of the mucosa supporting the dentures. Hayakawa et al., (2000) also pointed out to the correlation between maximum bite force and chewing efficiency, an aspect that was previously reported by Helkimo et al., (1983) and Uchida (1991).

Abdelnabi and Swelem (2020) also used transducers to investigate the effect of long term soft liners on vertical maximum biting force. Long term acrylic based soft liner was compared to the silicone based variety. Conventional heat cured acrylic resin was used as a control. They implemented a capacitive sensing technique for measurement. In their study, they used a layer of impression material to customize the contact between the transducer and the occlusal surface of the dentures. This approach was reported by van Kampen et al., (2002) and van der Bilt et al., (2008) to secure a reproducible position each time measurements were carried out. Each denture base material was used for a 3 months period in a cross over randomized controlled study design. By the end of the follow up period significant differences between the groups were reported with the silicone variety of soft liners being the most favorable followed by the acrylic resin long term soft liners and then the conventional acrylic resin group. It is worth mentioning that the differences between both varieties of soft liners were insignificant at the initial 1 and 2 months follow up period but was significant after 3 months. The interpretation put forward by the authors for the drop recorded with the acrylic based long term liners was the decline in the favorable viscoelastic behavior of the acrylic resin resilient liners due to leach out of plasticizer. The loss of plasticizer with time has been reported by Phoenix (2003), Mante et al., (2008), and Mese and Guzel (2008). 


\section{Effect on mandibular movements recorded during the chewing cycle}

Kimoto et al., $(2006,2010 \mathrm{~b})$ in two randomized controlled cross over studies implemented the BioPak system (Bioresearch) to investigate the effects of the two types of long term soft liners, namely silicone and acrylic resin, based on the patterns of mandibular movements during the chewing cycle. Both studies used conventional heat cured acrylic resin dentures as a control group. This system tracks a magnet attached to the mandibular complete denture at the area of the central incisor. The chewing cycle was analyzed after being divided into initial, middle and final phases. BioPak software was used to analyze the opening, closing and occluding times of the chewing cycles. It is worth mentioning that a prolonged early occluding stage was observed in silicone based long term soft liners and not in the control group (Kimoto et al., 2006). This positive finding was not reported with long term acrylic resin based soft liners (Kimoto et al., 2010b). This important result indicates that the favorable effect silicone soft liners have on the chewing cycle, and consequently on masticatory performance, takes place at the most challenging stage of chewing with complete dentures. At this initial phase of chewing, the food bolus applies considerable pressure on the supporting structures because the food bolus still retains its initial size and texture (Takayama et al., 2001; Nishigawa et al., 2003). Vinton and Manly (1955) reported that the most effective phase of mastication occurs when the separation between the maxillary and mandibular molars is around $2 \mathrm{~mm}$, in other words, close to the occluding phase of the masticatory cycle. The capacity of silicone long term soft liners to improve function and consequently comminute the food bolus at the early periods of the chewing cycle could be attributed to the ability of the resilient liner to widely distribute stresses on the supporting structures (Shim and Watts 2000). Resilient liners absorb impact forces from both functional and parafunctional mandibular movements (Diwan, 2003).

Unlike silicone based long term soft liners, the acrylic resin based variety resulted in insignificant differences in all tested chewing times, namely opening, closing and occluding (Kimoto et al., 2010b). This unfavorable outcome could be interpreted by the fact that different liners lose over time their softness to varying degrees based on their chemical composition. This adverse effect is due to a number of factors including absorption of oral fluids, plasticizer solubility, and also other components as unpolymerized and other soluble constituents into the saliva. This process is more evident in acrylic resin based long term soft liners in comparison to the silicone based variety (Wright, 1984; Jones et al., 1988; Mundsgaard, 2005; Mese and Guzel, 2008). Sofou et al., (2007) reported that silicone based in contrast to acrylic based liners have less monomer concentrations and thus less leachable content. Investigations of Brozek et al., $(2008,2011)$ identified more monomers and plasticizers in the acrylic based liners. Ethylene glycol dimethacrylate, a material added to increase cross linking is among the leached out materials. They thus reached the conclusion that cross linking was either incomplete or unstable. Chaldek et al., (2014) suggested that the leach out of such materials has to be further investigated. McCabe (1976) shared the same concern because of the potential toxicity of some of these leachable constituents.

\section{Effect on masticatory performance}

Van der Bilt (2011) reported that one of the techniques commonly implemented to evaluate masticatory performance is the sieving method. A predetermined weight of material to be chewed usually peanuts is masticated for a predetermined number of cycles on the side preferred by the test subjects (Manly and Braley, 1950). Higher masticatory performance corresponds to smaller sized pieces of test food after chewing (Kapur and Soman, 1964; Van der Bilt, 2011).

Kimoto et al., (2006) reported better masticatory performance with silicone based soft liners in comparison to conventional heat cured acrylic denture bases. They also pointed out that the masticatory performance improved significantly with time with the silicone liners and not with the conventional denture variety. The finding as regards conventional denture is in accordance with that of Vinton and Manly (1955). It was thus concluded that the denture base type has an impact on the process of patient adaptation to complete dentures. The authors accordingly recommended that patients using resilient liners should be informed that there will be a greater improvement of function with time. This piece of information will help patients not give up quickly on their dentures with resilient liners based on their previous experience with conventional dentures.

Tata and Nandeeshwar (2012) also compared silicone based liners to conventional heat cured dentures. They raised the question whether the elasticity of the soft liners might adversely affect the 
masticatory performance because of the assumption that extra force might be needed to compress soft liners and thus lead to muscle fatigue. The authors reported a highly significant $5 \%$ improvement in masticatory performance with silicone resilient liners. They agreed with the explanations put forward by other authors that attribute the favorable outcomes with soft liners to the more uniform distribution of forces under these materials (Qudah et al., 1990; Kawano et al., 1991; Kawano et al., 1993; Kawano et al., 1994; Shim and Watts, 2000) in addition to a reduction in the transmitted forces by a value that ranges from $20 \%-60 \%$ (Kawano et al., 1994).

Hayakawa et al., (2000) investigated the effect of fluoropolymer based long term soft liner in comparison to conventional heat cured acrylic resin complete dentures on masticatory performance. The study follow up period was only limited to 1 week. The findings were in accordance with the previous studies. The use of the soft liner resulted in a significant improvement with an increase of around 25\%. The authors reported that such an increase is comparable to levels observed in overdenture wearers as reported in the study of Nagasawa et al., (1979). They agreed with the interpretation of Emura et al., (1992) considering that the capacity of soft liners to deform results in the denture moving slightly to be in a more stable position, with an increased number of occlusal contacts and ultimately results in better masticatory performance.

On the contrary to the previous studies, Kimoto et al., (2010b) reported that the use of acrylic resin based soft liners did not result in significant differences in the masticatory performance when compared to conventional heat cured acrylic resin dentures. It is however worth mentioning that a possible interpretation for these results is the follow-up schedule implemented in this study $(3.8 \pm 1.5$ months). The authors suggested that due to plasticizer leach out from the acrylic resin based soft liner, the material resiliency and consequently the favorable impact of the soft liner on the masticatory performance was insignificant at the time of data collection.

\section{Effect on electromyographic recordings of the muscles of mastication}

Reviewing the dental literature revealed that a number of studies used electromyography as a methodology to assess the effect of long term soft liners (Hayakawa et al., 2000; Kimoto et al., 2006; Pisani et al., 2013).

Hayakawa et al., (2000) analyzed electromyographic recordings in complete dentures relined by fluoropolymer resilient liners as compared to conventional heat cured acrylic resin. Both right and left masseter muscles were monitored. The test food was peanuts. They assessed muscular task which includes chewing function from its beginning to the swallowing phase. Chewing time, number of strokes in addition to masticatory rhythm and muscle activity were investigated. The soft liner significantly improved electromyographic findings. A significant reduction of one fourth in the number of chewing strokes and another significant reduction of one third was observed in the chewing time. However, the reduction of the muscular activity in most of the participants was not statistically significant. The masticatory rhythm was more stable with the soft liner. The significant reduction in chewing strokes and time indicate the favorable impact of soft liners on masticatory function. In contrast to a previous study by Morimoto et al., (1984), the investigation of Hayakawa et al., (2000) included the initial stage of chewing when evaluating the chewing rhythm. The latter authors reported improvement in the early chewing stage and considered that an indication of comfort during denture wearing.

On the contrary, Kimoto et al., (2006) reported insignificant changes in electromyographic recordings between complete dentures relined with silicone and conventional heat cured acrylic resin. Right and left masseter muscles in addition to anterior temporalis were monitored. Peanuts were the test food chewed by the participants. Myoelectric integrated values were calculated at the initial, middle and final stages of chewing. Differences in electromyographic activity were insignificant for all muscles whether at working or the balancing side and in all chewing phases. The authors explained their findings by referring to one of their previous studies (Kimoto et al., 2004). They considered that the high level of satisfaction with both conventional dentures and those with soft liners is an indication that differences in electromyographic activity is minimal. The insignificant differences could be attributed to the case selection criteria in this study excluding cases with advanced resorption which made the treatment outcome with both soft liners and conventional dentures satisfactory. It is thus expected that electromyographic recordings will not be sensitive to detect slight differences between both treatment modalities. The authors explained the lack of agreement with the findings of 
Hayakawa et al., (2000) by the difference in study design. The study of Hayakawa et al., (2000) was a crossover 1-way trial. This study design emphasized the effect of the soft liner as it was implemented in the second phase of their investigation after the first phase which was wearing conventional dentures. This fixed sequence resulted in bias. On the other hand, the study of Kimoto et al., (2006) had a randomized 2-way cross over design, which avoided bias.

Pisani et al., (2013) investigated the effect of acrylic based hard liners versus silicone based soft liners on surface electromyograms recorded during both static and dynamic tasks. The static tests were carried out during maximum voluntary clenching in the intercuspal position, whereas dynamic tests were conducted with foods of different consistencies and hardness namely soft, moderately hard and hard. Muscles assessed were both right and left masseter and anterior temporalis. Both types of liners significantly improved the electromyographic recordings in comparison to the baseline dentures prior to relining. No significant differences were reported in the majority of test conditions between the hard and soft liners. This finding is consistent with that of Kimoto et al., (2006). The authors considered that result to be unexpected because it appears to contradict the commonly reported advantages of soft liners. The resilient liners are supposed to result in better load distribution, improved absorption of impact forces and greater comfort (Murata et al., 1998; Shim and Watts, 2000; Taguchi et al., 2001). These insignificant differences between the soft and hard liners could be attributed to the nature of the inclusion criteria. Cases enrolled in their study had only moderate residual ridge resorption with healthy resilient mucosa. This category of patients in the opinion of the authors will respond equally to hard and soft liners.

\section{Effect on patient centered outcomes}

The benefits of a treatment modality on the quality of life are one of the important factors that lead to success. McNaughter et al., (2001) emphasized that the perceptions of the patients are not always similar to those of their treating dentists. Patients are more concerned with how they feel about their dentures and not to the dentures' physical attributes. Reviewing the dental literature revealed the limited number of studies that evaluated Oral Health Related Quality of Life (OHRQoL) in the response to the use of soft liners (Pisani et al., 2012; Krunic et al., 2015).

Pisani et al., (2012) implemented the Brazilian version of Oral Health Impact Profile for assessing edentulous subjects (OHIP-EDENT) questionnaire to analyze OHRQoL at the time of denture insertion and 3 months after relining with silicone based long term soft liners. The Brazilian version of OHIP-EDENT has four domains: complaints related to mastication; psychological discomfort and disability; social disability; and lastly discomfort and pain (Souza et al., 2010). Patients reported a highly significant improvement in all four domains with the use of soft liners. Soft liners helped decrease some of the more common complaints from complete dentures namely: discomfort, pain and pressure; in addition to compromised retention and stability which results in less than ideal function and appearance (Quaran et al., 2001). Awad and Feine (1998) reported that the elements judged by denture wearers include: comfort, stability, ability to chew and speak, esthetics and ease of maintaining hygiene. It is worth mentioning that in the study of Pisani et al., (2012), all patients reported that relining with soft liner helped them eat their meals without interruptions. There was $62 \%$ reduction in sore areas. $93 \%$ of the participants showed psychological comfort and $100 \%$ reduction in embarrassment. $100 \%$ of the patients also reported improvement in social life and family tolerance.

Krunic et al., (2015) also used the OHRQoL as the patient centered outcome to evaluate the effect of relining maxillary complete dentures with silicone based long term soft liners. The opposing mandibular arch was restored with removable partial dentures. The control group had their maxillary dentures relined with hard acrylic resin based relining material. Their findings were in accordance with that of Pisani et al., (2012). Relining with silicone based long term soft liners had a significant positive impact on the OHRQoL domains namely: mastication, psychologic discomfort in addition to social disability, pain and oral hygiene. It is worth mentioning that both hard and soft relining material significantly improved OHRQoL, but the effect of the soft variety was more favorable.

Kimoto et al., (2004, 2008, 2010a, 2014) in a series of articles assessed patient centered outcomes with both silicone and acrylic based long term soft liners. Kimoto et al., (2004) investigated in their cross over study patient satisfaction and preference with silicone based long term soft liners versus conventional heat cured acrylic resin. They reported insignificant difference in satisfaction. 
Conversely, the significant majority of subjects (72\%) preferred the resilient liner variety. The authors interpreted the disparity between patient satisfaction measured on visual Analog Scale (VAS) and patient preference by the limitation of VAS in measuring patients' perception (Burns et al., 1995; Awad et al., 2000).

Kimoto et al., (2008) in a randomized controlled study evaluated patient satisfaction after the post-insertion appointment with acrylic based long term soft liners in comparison to conventional acrylic resin denture bases. They reported a dramatic improvement in satisfaction ratings in chewing, retention, stability, speaking, aesthetics, comfort, pain and cleaning after this short term use of the dentures.

In another randomized controlled clinical trial, Kimoto et al., (2010a) compared acrylic based long term soft liners with conventional acrylic resin denture bases. Recruited subjects were instructed to answer a questionnaire about their perceived chewing ability with 35 foods. The soft liner did not significantly impact the perceived chewing ability. The findings of this study are difficult to explain, especially when reviewing a previous article by the same authors that confirmed that acrylic based long term soft liners made chewing more comfortable (Kimoto et al., 2008). The authors interpreted their findings by referring to the findings of Allen and Locker (2002) and Ellis et al., (2008). They pointed out that patients experiencing long term edentulism with less than ideal prostheses tend to eventually avoid certain types of food. Prosthetic rehabilitation with new prostheses with even better quality does not necessarily lead to a change in the patient's diet, and hence their chewing ability remains unchanged.

Kimoto et al., (2014) in a 2 center randomized controlled trial further investigated satisfaction ratings with acrylic resin based soft liners as compared to conventional acrylic resin dentures. Additionally, a mastication index (MI) was calculated based on grading the perceived chewing ability. Significantly higher satisfaction ratings were reported with the resilient liner variety in: general satisfaction, chewing and speaking. The differences in MI were however insignificant. The authors interpreted the finding that $\mathrm{MI}$ in contrast to chewing satisfaction is affected by the number of daily food items that the complete denture wearer can consume. On the other hand, chewing satisfaction is rather influenced by the food consumption manner. Moreover, as reported by Gunji et al., 2009, patients with complete dentures of poor quality retain their compromised dietary habits even after receiving new dentures with higher quality and adequate functionality.

\section{Challenges in maintaining hygiene with soft liners}

Complete denture wearers encounter difficulties in maintaining hygiene of soft relined dentures. These hardships are attributed to some unfavorable inherent properties of soft liners. This category of materials has reduced resistance to scratching because of the low surface hardness and compromised bond strength to the denture base. Porosity in addition to high water sorption further compromise soft liners and make hygiene maintenance a concern (Chladek et al., 2014). Commonly used denture cleansers showed detrimental effects on the surface characteristics of these materials. Oliveira et al., (2007) and Brozek et al., (2011) reported that stain and roughness frequency were affected by factors related to the type of denture cleaner used and the frequency of its application. Also, the brushing method used had an impact. Such shortcomings were not observed in denture wearers using conventional acrylic resin with no soft liners.

A major concern with long term soft liners is colonization with microorganisms especially fungi. Evidence suggests that this problem is still an unresolved limitation with the available materials (Chladek et al., 2014). Skupien et al., (2013) concluded that nystatin incorporated in soft liners proved to be effective for only a short period. Chladek et al., $(2011,2013)$ investigated the effect of incorporating different concentrations of silver nanoparticles in silicone based soft liners. Longevity of the antimicrobial effect of silver particles has still to be analyzed. Chladek et al., (2013) reported other concerns namely the consequences of nanosilver on the mechanical properties of the soft liners in addition to problems of discoloration. A suggested alternative is the use of ceramic nanofillers that possess antimicrobial properties to overcome some of the above-mentioned limitations.

Oguz et al., (2007) and Kasuga et al., (2011) observed that silicone based soft liners show more color stability when compared with the acrylic based variety. Anil et al., (1999), Jin et al., (2003) and Oguz et al., (2007) investigated color stability of heat-polymerized versus auto-polymerized soft liners and concluded that the former is superior in this respect. Sarac et al., (2007) reported that the 
different denture cleaners show variations in effectiveness of stains removal from food and some level of visible staining persists after cleaning. Handa et al., (2008) and Goiato et al., (2009) emphasized the modulating effect of temperature and thermal cycling of the water used to dissolve denture cleaning agents on their efficiency.

\section{Limitations of studies investigating long term soft liners}

Most of the studies that assessed clinical outcomes of long term soft liners recruited completely edentulous subjects with good prognosis. The complete denture treatment was carried in an academic environment with frequent recall visits. Most of study participants had already satisfactory conventional complete denture. In the vast majority of published studies the use of soft liners had a positive impact that was perceived favorably by the patients preferring denture with soft liners over conventional complete denture. These positive findings did not always correspond to statistically significant objective clinical outcomes (Kimoto et al., 2004; Kimoto et al., 2006; Pisani et al., 2012). It is thus recommended to carry out such studies on patients who will really benefit from soft liners. Dental literature still lacks such clinical investigations. Palla et al., (2015) had the opinion that the improvement in clinical and patient centered outcomes will be more obvious in complete denture wearers who suffer persistent pain and compromised function as a consequence of less than ideal anatomic features. They suggested that the functionality of this category of complete denture wearers could be an area of focus of upcoming clinical studies.

\section{References}

Abdelnabi M.H., and A.A. Swelem, 2020. Silicone versus acrylic resilient long term soft liners; a cross-over clinical study. Curr Sci Int., 9: 1-11.

Allen, F., and D. Locker, 2002. A modified short version of the oral health impact profile for assessing health-related quality of life in edentulous adults. Int J Prosthodont .15:446-450.

Anil, N., C. Hekimoglu and S. Sahin, 1999. Color stability of heat-polymerized and autopolymerized soft denture liners. J. Prosthet. Dent., 81: 481-484.

Awad, M.A., and J.S. Feine, 1998. Measuring patient satisfaction with mandibular prostheses. Community Dent Oral Epidemiol., 26: 400-405.

Awad, M.A., D. Locker, B.N. Korner and J.S. Feine, 2000. Measuring the effect of intra-oral implant rehabilitation on health-related quality of life in a randomized controlled clinical trial. J Dent Res., 79: 1659-1663.

Braden, M., P.S. Wright and S. Parker, 1995. Soft lining materials -A review. Eur. J Prosthodont. Restor. Dent., 3: 163-174.

Brożek R., R. Rogalewicz, R. Koczorowski and A. Voelkel, 2008. The influence of denture cleansers on the release of organic compounds from soft lining materials. J. Environ. Monit., 10, 770-774.

Brozek, R., R. Koczorowski, R. Rogalewicz, A. Voelkel, B. Czarnecka and J.W. Nicholson, 2011. Effect of denture cleansers on chemical and mechanical behavior of selected soft lining materials. Dent Mater, 27: 281-290.

Burns, D.R., J.W. Unger, R.K.Jr. Elswick and J.A. Giglio, 1995. Prospective clinical evaluation of mandibular implant overdentures: Part II-Patient satisfaction and preference. J Prosthet Dent . 73:364-369.

Chladek, G., A. Mertas, I. Barszczewska-Rybarek, T. Nalewajek, J. Żmudzki, W. Król, and J. Łukaszczyk, 2011. Antifungal Activity of Denture Soft Lining Material Modified by Silver Nanoparticles-A Pilot Study. Int. J. Mol. Sci., 12: 4735-4744.

Chladek, G., J Kasperski, I. Barszczewska-Rybarek and J. Żmudzki, 2013. Sorption, Solubility, Bond Strength and Hardness of Denture Soft Lining Incorporated with Silver Nanoparticles. Int. J. Mol. Sci., 14: 563-574.

Chladek, G., J. Zmudzki and J. Kasperski, 2014. Long-Term Soft Denture Lining Materials. Materials (Basel), 12; 7(8): 5816-5842.

Diwan, R.R., 2003. Material prescribed in the management of edentulous patients. In: Zarb GA, Bolender CL, Eckert SE, Jacob RF, Fenton AH, Mericske-Sterm R (eds). Prosthodontic Treatment for Edentulous Patients: Complete Dentures and Implant-Supported Prostheses. St Louis: Mosby, 198-202 
Douglass, C.W., A. Shih, and L. Ostry, 2002. Will there be a need for complete dentures in the United States in 2020? J Prosthet Dent., 87:5-8

Ellis, J.S., J.M. Thomason, N.J. Jepson, F. Nohl, D.G. Smith and P.F. Allen, 2008. A randomizedcontrolled trial of food choices made by edentulous adults. Clin Oral Implants Res., 19:356-361.

Emura, I., S. Idoji, Y. Maeda, M. Okada, T. Nokubi and Y. Okuno, 1992. Effect of resilient lining material of denture base-Clinical investigation and model experiment on occlusal force distribution. J Jpn Prosthodont Soc., 36:644-649.

Feine, J.S., G.E. Carlsson, M.A. Awad, A. Chehade, W.J. Duncan, S. Gizani, T. Head, G. Heydecke, J.P. Lund, M. MacEntee, R. Mericske-Stern, P. Mojon, J.A. Morais, I. Naert, A.G. Payne, J. Penrod, G.T. Stoker, A. Tawse-Smith, T.D. Taylor, J.M. Thomason, W.M. Thomson and D Wismeijer, 2002. The McGill consensus statement on overdentures. Mandibular two-implant overdentures as first choice standard of care for edentulous patients. Int J Oral Maxillofac Implants, 17:601-2.

Felton, D., L. Cooper, I. Duqum, G. Minsley, A. Guckes, S. Haug, P. Meredith, C. Solie, D Avery, and $\mathrm{N}$ Chandler, 2011. Evidence based guidelines for the care and maintenance of complete dentures. J Prosthodont., 20:1-12.

Goiato, M.C., R.M. Falcón-Antenucci, D.M. Santos and E.P. Pellizzer, 2009. Evaluation of hardness and color stability in the soft lining materials after thermocycling and chemical polishing. Acta Odontol. Latinoam., 22, 63-68.

Gunji, A., S. Kimoto, H. Koide, H. Murakami, Y. Matsumaru, K. Kimoto, M. Toyoda and K. Kobayashi, 2009. Investigation on how renewal of complete dentures impact on dietary and nutrient adequacy in edentulous patients. J. Prosthodont, Res., 53:180-184.

Handa, R.K., D.C. Jagger, and R.W. Vowles, 2008. Denture cleansers, soft lining materials and water temperature: What is the effect? Prim. Dent. Care, 15: 53-58.

Hayakawa, I., S. Hirano, Y. Takahashi and E.S. Keh, 2000. Changes in the masticatory function of complete denture wearers after relining the mandibular denture with a soft denture liner. Int $\mathrm{J}$ Prosthodont, 13: 227-231.

Helkimo, E., M.R. Heath, and M.T.M. Jiffery, 1983. Factors contributing to mastication: An investigation using 4 different test foods. J. Oral Rehabil., 10:431.

Jin, C., H. Nikawa, S. Makihira, T. Hamada, M. Furukawa, and H. Murata, 2003. Changes in surface roughness and colour stability of soft denture lining materials caused by denture cleansers. J. Oral Rehabil., 30: 125-130.

Jones, D.W., E.J. Sutow, G.C. Hall, W.M. Tobin, and B.S. Graham 1988. Dental soft polymers: plasticizer composite and leachability. Dent Mater. Feb; 4(1):1-7.

Kalachandra, S., R.J. Minton, D.F. Taylor, and T. Takamata, 1995. Characterization of some proprietary soft lining materials. J. Mater Sci. Mater Med., 6:647-652.

Kapur, K.K., and S.D. Soman, 1964. Masticatory performance and efficiency in denture wearers. J Prosthet Dent. 2006 Jun; 95(6):407-11

Kasuga, Y., H. Takahashi, N. Akiba, S. Minakuchi, N. Matsushita, and M. Hishimoto, 2011. Basic evaluation on physical properties of experimental fluorinated soft lining materials. Dent. Mater. J., 30: 45-51.

Kawano, F., N. Tada, K. Nagao and N. Matsumoto, 1991. The influence of soft lining materials on pressure distribution. J. Prosthet. Dent., 65:567-75.

Kawano, F., A. Koran, K. Asaoka, and N. Matsumoto, 1993. Effect of soft denture liner on stress distribution in supporting structures under a denture. Int. J. Prosthodont, 6:43-49.

Kawano, F., M. Kon, A. Koran, and N. Matsumoto, 1994. Shock- absorbing behaviour of four processed soft denture liners. J. Prosthet., Dent., 72:599-605.

Kiat-Amnuay, S., L. Gettleman, T. Mekayarajjananonth, Z. Khan, and L.J. Goldsmith, 2005. The influence of water storage on durometer hardness of 5 soft denture liners over time. J. Prosthet. Dent., 14: 19-24.

Kimoto, S., M. Kitamura, M. Kodaira, S. Yamamoto, Y. Ohno, Y. Kawai, M. Kawara, and K. Kobayashi, 2004. Randomized controlled clinical trial on satisfaction with resilient denture liners among edentulous patients, Int. J. Prosthodont., 17: 236-240.

Kimoto S., S.O. Kimoto, K. Kimoto, S. Yamaoto, Y. Onho, M. Shimomiya, K. Ogura and K. Kobayashi, 2006. Randomized controlled clinical trial for verifying the effect of silicone based 
resilient denture liner on the masticatory function of complete denture wearers, Int. J. Prosthodont., 19(6): 593-600.

Kimoto S, K. Kimoto, A. Gunji, Y. Kawai, H. Murakami, K. Tanaka, K. Syu, H. Aoki, M. Tani, M. Toyoda, and K. Kobayashi, 2008. Effects of resilient denture liner in mandibular complete denture on the satisfaction ratings of patients at the first appointment following denture delivery, J. Jpn. Prosthodont. Soc., 52: 160-166.

Kimoto, S., K. Kimoto, A. Gunji, M. Shinomiya, T. Sawada, M. Saita and K. Kobayashi, 2010a. Randomized controlled trial investigating the effect of an acrylic-based resilient liner on perceived chewing ability in edentulous patients wearing mandibular complete dentures. Int. J. Prosthodont, 23:110-116.

Kimoto, S., S. Yamamoto, M. Shinomiya and Y. Kawai, 2010b. Randomized controlled trial to investigate how acrylic-based resilient liner affects on masticatory ability of complete denture wearers. J Oral Rehabil., 37:553-559.

Kimoto, S., K. Kimoto, H. Murakami, G. Atsuko, A. Ogawa and Y. Kawai, 2014. Effect of an acrylic resin-based resilient liner applied to mandibular complete dentures on satisfaction ratings among edentulous patients. Int. J. Prosthodont., 27(6):561-6.

Krunic, N., M. Kostic, M. Petrovic and M. Igic, 2015. Oral health-related quality of life of edentulous patients after complete dentures relining. Vojnosanit Pregl., 72(4):307-11.

Manly, R.S., and L.C. Braley, 1950. Masticatory performance and efficiency. J. Dent. Res., 29:448462.

Mante, F.K., M.O. Mante, and V.C. Petropolous, 2008. In vitro changes in hardness of sealed resilient lining materials on immersion in various fluids. J. Prosthodont., 17: 384-391.

McCabe, J., 1976. Soft lining materials: Composition and structure. J. Oral Rehabil, 3: 273-278.

McNaugher, G.A., I.C. Benington, and R. Freeman, 2001. Assessing expressed need and satisfaction in complete denture wearers. Gerodontology, 18: 51-57.

Mese, A. and K.G. Guzel, 2008. Effect of storage duration on the hardness and tensile bond strength of silicone- and acrylic resin-based resilient denture liners to a processed denture base acrylic resin. J. Prosthet. Dent., 99: 153-159.

Morimoto, T., T. Inoue, T. Nakamura, and Y. Kawamura, 1984. Frequency dependent modulation of rhythmic human jaw movements. J. Dent. Res., 63:1310-1314.

Munksgaard, E.C., 2005. Plasticizers in denture soft-lining materials: leaching and biodegradation. Eur J Oral Sci. Apr., 113(2):166-9.

Murata H, RC Haberham, T Hamada, and N. Taguchi, 1998. Setting and stress relaxation behavior of resilient denture liners. J. Prosthet. Dent., 80: 714-722.

Murata H., N. Taguchni, T. Hamada, M. Kawamura and J.F. McCabe, 2002. Dynamic viscoelasticity of soft liners and masticatory function, J. Dent. Res., 81(2): 123-128.

Nagasawa, T., H. Okane, and H. Tsuru, 1979. The role of the periodontal ligament in the overdenture treatment. J. Prosthet Dent., 42:12-16.

Nishigawa, G., T. Matsunaga, Y. Maruo, M. Okamoto, N. Natsuaki and S. Minagi, 2003. Finite element analysis of the effect of the bucco-lingual position of artificial posterior teeth under occlusal force on the denture supporting bone of the edentulous patient. J. Oral Rehabil, 30:646652.

Oğuz, S., M.M. Mutluay, O.M. Doğan and B. Bek, 2007. Color change evaluation of denture soft lining materials in coffee and tea. Dent. Mater. J., 26: 209-216.

Oliveira, L.V., M.F. Mesquita, G.E. Henriques and R.L. Consani, 2007. The effect of brushing on surface roughness of denture lining materials. J. Prosthodont, 16: 179-184.

Palla ES, E Karaoglani, O Naka, and V Anastassiadou, 2015. Soft denture liners' effect on the masticatory function in patients wearing complete dentures: A systematic review. J Dent; 43(12):1403-10.

Petersen, P.E., D. Bourgeois, D. Bratthall and H. Ogawa, 2005. Oral health information systemstowards measuring progress in oral health promotion and disease prevention. Bull World Health Organ, 83:686-693.

Phoenix, R.D., 2003. Denture base resins. In Phillips' Science of Dental Materials, $11^{\text {th }}$ ed., Anusavice, K., Ed., Saunders: St. Louis, MO, USA, 750-752. 
Pisani, M.X., L. Malheiros-Segundo Ade, K.L. Balbino, R.F. de Souza, F. Paranhos Hde and C.H. da Silva, 2012. Oral health related quality of life of edentulous patients after denture relining with a silicone-based soft liner. Gerodontology. Jun., 29(2):e474-80.

Pisani, M.X., A.L. Segundo, V.M. Leite, R.F. de Souza, M.A. da Silva and C.H. da Silva, 2013. Electromyography of masticatory muscles after denture relining with soft and hard denture liners, J. Oral Sci., 55: 217-224.

Qudah, S., A. Harrison and R. Huggett, 1990. Soft lining materials in prosthetic dentistry: A review. Int J Prosthodont, 3:477-83.

Quaran, F.A.L., T. Clifford, C. Cooper and P.J. Lamey, 2001. Influence of psychological factors on the acceptance of complete dentures. Gerodontology, 18: 35-40.

Rodrigues, S., Shenoy, V. Shetty, and T. Resilient liners: A review, 2013. J. Indian Prosthodont. Soc., 13: $155-164$.

Saraç, D., Y.S. Saraç, M. Kurt and E. Yüzbaşioğlu, 2007. The effectiveness of denture cleansers on soft denture liners colored by food colorant solutions. J. Prosthodont., 16:185-191.

Schmidt, W.F.Jr. and D.E. Smith, 1983. A six-year retrospective study of Molloplast-B-lined dentures. Part I: Patient response. J Prosthet Dent., 50(3):308-13.

Shim, J.S. and D.C. Watts, 2000. An examination of the stress distribution in a soft-lined acrylic resin mandibular complete denture by finite element analysis. Int. J. Prosthodont, 13: 19-24.

Shinomiya, M., 2006. In-vivo and in vitro studies for analysis of mastication in complete denture wearers with resilient denture liners, Int. J. Oral-Med. Sci., 2(5): 107-116.

Skupien, J.A., F. Valentini, N. Boscato and T. Pereira-Cenci, 2013. Prevention and treatment of Candida colonization on denture liners: A systematic review. J. Prosthet. Dent., 110: 356-362.

Sofou, A., I. Tsoupi, M. Karayannis, and B. Owall, 2007. Determination of residual monomers released from soft lining materials with the use of HPLC. Pak. J. Anal. Environ. Chem., 8: 4152.

Souza, R.F., L. Patrocino, A.C. Pero, J. Marra, and M.A. Compagnono, 2007. Reliability and validation of a Brazilian version of the Oral Health Impact Profile for assessing edentulous subjects. J Oral Rehabil, 34: 821-826.

Souza, R.F., C.R. Leles, G.H. Guyatt, C.B. Pontes, M.P. Della Vecchia, and F.D. Neves, 2010. Exploratory factor analysis of the Brazilian OHIP for edentulous subjects. J Oral Rehabil., 37: 202-208.

Taguchi, N., H. Murata, T. Hamada, and G. Hong, 2001. Effect of viscoelastic properties of resilient denture liners on pressures under dentures. J. Oral Rehabil, 28: 1003-1008.

Takayama, Y., T. Yamada, O. Araki, T. Seki and T. Kawasaki, 2001. The dynamic behaviour of a lower complete denture during unilateral loads: Analysis using the finite element method. J Oral Rehabil, 28: 1064-1074.

Tata, S., and D.B. Nandeeshwar, 2012. A clinical study to evaluate and compare the masticatory performance in complete denture wearers with and without soft liners, J. Contemp. Dent. Pract. 13: 787-792.

The Glossary of Prosthodontic Terms: Ninth Edition, 2017. J Prosthet Dent., 117(5S):e1-e105. doi: 10.1016/ j.prosdent. 2016.12.001. PMID: 28418832.

Uchida, T., 1991. Study on evaluation of masticatory function of complete denture wearers-Factors influencing masticatory function and proper test foods for evaluation. J Stomatol Soc Jpn; $58: 182-197$.

Udo-Yamakawa, A. and Y. Kawai, 2010. Effects of home and office care denture reliners on maxillary complete dentures, Gerodontology, 27: 141-146.

Van der Bilt, A., F.A. Tekamp, H.W. van der Glas and J.H. Abbink, 2008. Bite force and EMG during maximum unilateral and bilateral clenching. Eur. J. Oral. Sci., 116:217-222.

Van der Bilt, A., J. Mojet, F.A. Tekamp, and J.H. Abbink, 2010. Comparing masticatory performance and mixing ability. J. Oral Rehabil. Feb., 37(2):79-84.

Van der Bilt, A., 2011. Assessment of mastication with implications for oral rehabilitation: a review. J Oral Rehabil, 38:754-780.

Van Kampen, F.M.C., A. van der Bilt, M.S. Cune and F. Bosman, 2002. The influence of various attachment types in mandibular implant-retained overdentures on maximum bite force and EMG. J Dent Res., 81:170-173. 
Vinton, P. and R.S. Manly, 1955. Masticatory efficacy during the period of adjustment to dentures. J Prosthet Dent., 5:477-480.

Wright, P.S., 1984. The success and failure of denture soft-lining materials in clinical use. J Dent. Dec., 12(4):319-27.

Wright, P.S., 1994. Observations on long-term use of a soft lining material for mandibular complete dentures. J. Prosthet. Dent., 72: 385-392. 